\title{
Gaming Concepts for Tackling Societal Challenges: A Preliminary Survey and Analysis
}

\author{
Edward Jaser $^{1}$, Yazan Doofesh ${ }^{1}$, Luminita Mihalachi ${ }^{2}$
}

${ }^{1}$ Computer Graphics and Animation, Princess Sumaya University for Technology, Amman-Jordan ejaser@psut.edu.jo

${ }^{2}$ Information Society Development Institute, ISDI, Chișinău - Moldova

\section{ABSTRACT}

Imihalaki@gmail.com

\begin{abstract}
Governments, and to a certain extent non-governmental organizations, around the world have to continuously deal with complex and dynamic societal challenges. One approach that has gained increasing popularity over the last two decades is the use of Information and Communication Technologies (ICT) as a tool to enhance impact and deliver efficiency and effectiveness. Therefore, we have been witnessing wide spectrum of ICT interventions to address and inhibit challenging and complex societal problems. One area of ICT that has been attracting more attention recently is the use of games and gaming concepts for this purpose. In this paper, we provide analysis about major societal challenges that are shared internationally and analyse video games that are designed to address these challenges
\end{abstract}

\section{Indexing terms/Keywords}

ICT, societal challenges; video games; gamification; Serious games.

\section{Type (Method/Approach)}

Literary Analysis; Survey

\section{Council for Innovative Research}

Peer Review Research Publishing System

\section{Journal: INTERNATIONAL JOURNAL OF COMPUTERS \& TECHNOLOGY}

Vol 12, No. 5

editor@cirworld.com 


\section{INTRODUCTION}

We are facing today a number of complex and challenging societal problems. It is a daunting task to fully understand the dynamics of these challenges as their causes are difficult to map and identify. Certainly human activities play a central role in shaping these societal challenges. By nature, these challenges have an impact on large number of the population and therefore, are active discussion topic for public debates. One well known fact is that governments around the world are injecting considerable efforts and resources to well identify and prioritize community problems. Naturally, this will be followed by forging plans and actions to solve these problems or, more realistically, lessen their effects. Typically, each country is faced with its own challenges, but increased numbers of challenges are becoming global especially with the movement of population, whether forced or not, across continents.

Information and Communication Technologies (ICTs) have been successfully deployed as a tool to tackle various challenges. ICTs are widely considered as the motor of growth, the driver of efficiency and effectiveness and the tool to enhance productivity and impact. With the advancement of ICTs and the Internet, communication and web-based technologies can be exploited to address many challenges with relation to improving coverage and obtaining a much needed accurate statistics and information. In recent years, there have been concrete evidences on the impact of social networking website in many aspects of life. An obvious and recent example is current events in the Middle East and North Africa dubbed as the Arab Spring. Many claim major roles for social networking tools such as Facebook and Twitter in the dynamics of these events [1]. These tools are changing the way people communicate, receive and exchange information. As a logical result ICT became an indispensable tools for governmental bodies and non-governmental organizations to conduct their activities more efficiently and in a timely manner. Appreciating the benefits ICTs bring, governments are continuously improving ICT infrastructure such as fiber optic networks, internet connectivity and speed and mobile coverage. We can read many success stories which demonstrate ICT interventions that have been deployed to address social challenges, such as those facing rural communities. Cespedes et al. [2] discussed the impact of mobile technology in improving revenue from agricultural activities in Latin America and the viability of this technology in enhancing productivity, facing poverty, and improving social conditions in general. ICT reported a significant impact in promoting health status of women and children in remote and rural communities of Jordan [3], [4], [5]. The intervention proposed in these work helped improving non-vaccination rate in rural Jordan. It also helped in providing the government of Jordan and NGOs operating in rural Jordan with the tool to disseminate information and significantly improve medical knowledge outreach to moving population and remote communities. Of course we can see many similar examples with positive feedback in Africa, Latin America and Asia.

We believe that ICT for Development (ICTD) has gained great attention and are enjoying many success stories and understandably are becoming part of any development and research initiatives. This has been evident in the huge share of funding under the Horizon2020 [6], [7] in which more than 30K million have been dedicated to address major concerns and problems facing European communities. This include addressing challenges related to health, climate change, transport and mobility, renewable energy, food safety and security and the challenges associated with ageing population. Horizon2020 will attract significant research work in ICT for addressing societal challenges.

To focus more on the topic of this paper, we will address one field of ICT that have interesting potentials that we believe have not been exploited to a significant extent: Digital Games and Gaming concepts. Digital games are phenomenally becoming a significant part of our daily life. The fact that digital games are having increased influence on many sectors: culture, technology, politics, art, economy and others has made it an active research topic and the focus of many studies investigating their impact on society. There are subfields in gaming research that have been widely investigated and used recently: Gamification and Serious games. Gamification refers to "the use of design elements characteristic for games in non-game contexts regardless of specific usage intentions, contexts, or media of implementation" [16]. It attracted and motivated usage in interaction design in numerous applications. The other term "Serious video games" [17] refer to games that are developed with the aim to educate, train, or change behavior while having the enjoyment of playing games. Interest in both Gamification and serious games has been witnessing a rapid growth as well as popularity, especially with government and NGO sectors. It will be interesting to be able to better understand what impact digital games can have, maybe in some cases is having, on addressing the community problems and challenges.

In this paper, we look into this important research question and look into video games as a tool to help address societal challenges. There have been many attempts to develop video games to tackle some of these challenges. Some games have reported positive impact but many have been unsuccessful if we judge based on engagement. We report in this paper our work on understanding current community challenges as identified by the various stakeholders and map it to a survey we conducted that can be considered as addressing these challenges. We also provide our views and analysis about this mapping.

The paper is organized as follows. In Section 2, we look into the main societal challenges. In Section 3, we survey the game industry to identify those game that can be qualifies as games that address societal challenges. We provide an analysis based on our survey in Section 4. We conclude the paper in Section 5.

\section{SOCIETAL CHALLENGES}

It is always an interesting topic and a source of heated debate when discussing the most pressing societal challenges facing a country. As mentioned earlier, it is difficult to fully understand the complex dynamics of problems facing communities. However, looking at the efforts done by many governments across the world, one can identify the main problems that constitute major concerns for societies. 
Among the most pressing challenges are health issues, health services and health awareness. Communities all around the world face a growing number of major and complex health problems. This include: (i) Obesity, which is a major public health challenge in developed and developing countries of this century; (ii) health services to underserved or remote communities in rural areas as well as displaced population; (iii) ageing population, one of Europe pressing challenges; (iv) health issues related to modern society, mainly psychological stress; (v) access to accurate, reliable and relevant health information suitable for average citizen; (vi) increased cases of COPD, cancer, diabetes and cardiovascular diseases.

Another challenge that is gaining attention recently is efficient use of resources [6]. This include: (i) lowering energy consumption and reducing greenhouse gas emissions; (ii) water management and reducing water consumption. This also have direct link to challenges concerning climate change and protecting the environment. Tackling these kinds of challenges is associated mainly with changing behavior which is best done through awareness.

Other challenges that are shared globally, but maybe with varying degrees from one country to another and varying causes and effects, include: (i) corruption; (ii) the inequality of public services especially the urban/rural issue; (iii) education; (iv) growing problems in, due to modern society and moving population, communication and social skills of children; (v) weak social cohesion; (vi) citizens' awareness of individual rights and responsibilities.

The EU has launched a new framework program for research and innovation famously known as Horizon2020. The program provides a clear indication about the importance of tackling societal challenges. $43 \%$ of the total budget for the program (72billion euros) is dedicated to this purpose. Fig 1 list the main societal challenges addressed by the program.

\section{Societal Challenges (43\%)}

\begin{tabular}{|c|c|c|c|c|c|c|}
\hline $\begin{array}{l}\frac{I}{D} \\
\frac{\varrho}{\mp} \\
\frac{+}{J}\end{array}$ & 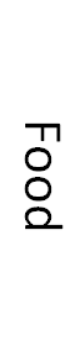 & 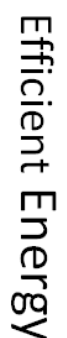 & $\begin{array}{l}\text { n } \\
3 \\
\frac{0}{2} \\
-1 \\
\frac{1}{2} \\
\frac{0}{2} \\
\frac{n}{0} \\
\frac{0}{7}\end{array}$ & 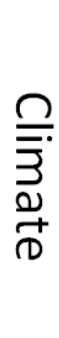 & 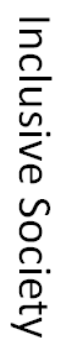 & 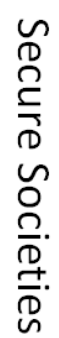 \\
\hline
\end{tabular}

Fig 1: The EU Horizon 2020 Societal Challenges

Of course there are many more challenges that the reader of this paper can think of and are justifiably important. We are aiming from this paper to identify some key challenges at global level and survey/study the appropriateness of gaming concepts to help inhibit their effects. Table 1 summarizes the main key challenges we identified.

Table 1. Main Societal Challenges with Global Impact

\begin{tabular}{|c|c|}
\hline Field & Challenges \\
\hline Health & $\begin{array}{l}\circ \text { Obesity } \\
\circ \text { Supporting patients } \\
\circ \text { Health awareness } \\
\circ \text { Equality }\end{array}$ \\
\hline $\begin{array}{l}\text { Efficient use of } \\
\text { resources }\end{array}$ & $\begin{array}{l}\text { o Saving energy } \\
\circ \text { Waste management } \\
\circ \text { Gas emission } \\
\circ \text { Climate change }\end{array}$ \\
\hline Education & $\begin{array}{l}\text { Social skills } \\
\text { Science Technology Engineering and Mathematics } \\
\text { (STEM) }\end{array}$ \\
\hline Social aspects & $\begin{array}{l}\circ \text { Equality } \\
\circ \text { Participation }\end{array}$ \\
\hline
\end{tabular}




\begin{tabular}{|l|l|}
\hline & $\circ$ Citizens' awareness \\
& $\circ$ Digital divide \\
○ Moving population \\
$\circ$ Weak social cohesion \\
& $\circ$ Political/Governance issues \\
\hline
\end{tabular}

\section{GAMES ADDRESSING SOCIETAL CHALLENGES}

For the aforementioned challenges, we looked into games that have direct or indirect impact in tackling them. We focused on the gameplay to categorize these games as it is "the components that make up a rewarding, absorbing, challenging experience that compels the player to return for more" [8]. We subjectively map the games we investigated to the challenges we identified earlier in Table I. The mapping is provided in the following sections and summarized in Table 2.

\subsection{Health}

Obesity as a health challenge has been approached by games. One successful game is Easy Eater [9]. This game is developed by JiveHealth and is aimed to fight children obesity. The gameplay involve allowing children to check in food based on what they ate in exchange for points and rewards. The game promotes and encourages healthy eating. Positive feedback has been reported though no solid evaluation methodology was provided. Another game that had a sounding impact is Dance Dance Revolution (DDR) [10]. It has a simple gameplay which motivates physical interaction from the players in the form of stepping their feet to correspond with the arrows that appears on screen as well as to the music. Many players have reported weight loss. This has triggered and motivated deployment at schools and universities to be part of the required physical exercise. DDR is part of what is widely known as Active Video Games [11] which are video games "that requires physical activity beyond that of a passive game (i.e., conventional hand-held games)" and "rely on technology that tracks body movement or reaction for the game to progress".

Games to help patients through difficult and painful treatments have been developed and used. One classical example is the Immersive virtual reality pain distraction game SnowWorld [12]. The game is designed to help burn patients. Research outputs showed that using the game helped significantly in reducing "feeling pain" while undergoing painful burn treatment. For patient with cancer, Re-Mission 2 [13] has been developed to help children fight the disease and facilitate the treatment. The gameplay have the player enter the human body and fight cancer using chemotherapy, antibiotics beside the body's natural defenses as weapons. The game was intended to provide knowledge and information about how cancer treatment work and help give patients much needed positive energy. It was reported that the games boosted self-efficacy and positive emotions and by raising awareness about chemotherapy. Theme Hospital [14] is another health related game which can help in raising awareness about hospital management and medical terms. The player can assign the staff (Doctors, Receptionists, and Janitors) and give them special and specific tasks to perform (research, surgery, psychology...etc.).

\subsection{Education}

In education, many examples on using games to support and facilitate the educational process can be found. An obvious example is games developed by WonderVille (www.wonderville.ca). Many games have been developed with the aim to provide children with "interactive destination to discover the exciting world of science". Example games include: (i) The Science of Waste: managing and monitoring of waste materials; (ii) Solar Energy Defenders: Awareness about solar energy in the form of a game; (iii) $\mathrm{CO} 2$ Connection: reducing the carbon footprint; (iv) Save The World: awareness about energy supplies and alternative energy sources (renewable energy); (v) WasteAvengers: environmental online game teach about waste disposal techniques, reuse and recycle.

\subsection{Politics/Governance}

Games have also been attempted to solve extremely complex political situations. PeaceMaker [15] is a serious video game released in 2007 by ImpactGames and is aimed at promoting peace. The idea behind the game is to allow players to assume one role of the main decision makers in the Israeli-Palestinian conflict (i.e., the Prime Minister of Israel or the President of the Palestinian Authority) and strategically make decisions to try to solve the conflict. The game has received good reviews. This has triggered wide distribution of the game to Israeli and Palestinian students with the aim to encourage peaceful debate and discussions.

As evidence to the importance of games in improve and increase youth political participation and civic engagement in local governance, the UNDP in cooperation with a leading university in Jordan designed and developed a game about "Youth Participation in Local Governance" (www.youth.gov.jo). The aim of the game was to raise awareness on how important to participate in making the community a better place by giving their opinion and how this effort reflects well on them and their lifestyle in return. Another NGO to utilize games is the UN World Food Program. They developed FoodForce [16] a game that helps raise awareness about famine and food distribution. The game play consists of six missions in which the player have to fight famine and deal with food shortages and help build food resources. 


\subsection{Social Aspects}

An interesting example of serious games to impact social behavior at children level is Village Voices [17] game. It is an adaptive serious game designed to support children in learning about conflict resolution. Children assume the role of individual villagers "who need to work through the various conflicts that arise in the game world". One interesting aspect of this game is the evaluation which took place in three countries using school students as testing subjects. Preliminary feedbacks are showing good reviews. Also, and to achieve a positive change in behavior, the author in [23] developed the Creature -101 game to promote healthy eating behaviors and improve physical activities among middle school students. The authors provided interesting and detailed evaluation scenarios, using school students, to better understand game impact.

\subsection{Energy and Resources}

To tackle limited resources and the challenge concerning the increasing demand of energy, the EU funded project Save Energy has been deploying gaming technology as a tool to achieve behavior transformation "as an enabler of energy efficiency" in five Public building. They designed serious games Green My Place (greenmyplace.net) to help achieve this transformation. This is one of few examples in which a project has been granted EU fund to develop a serious game to achieve main objectives.

Table 2. Games as a tool to tackle challenges

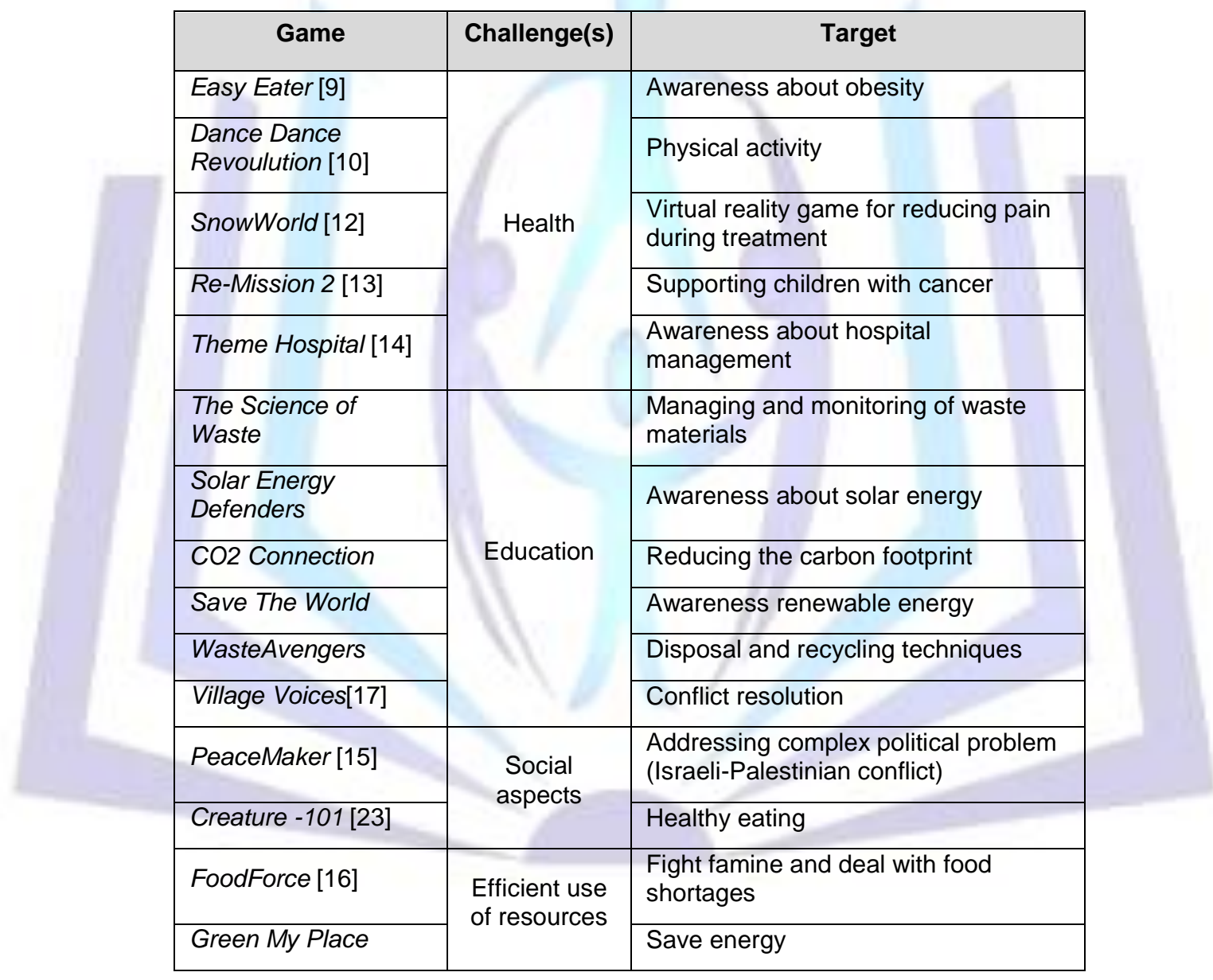

\section{ANALYSIS}

It is clear that games and gaming concepts are playing an important role in addressing societal challenges. Perhaps the form this role is taking is significantly about raising awareness. Without a doubt, these games are successful as there are increasing researchers who are investigating this technology and are thoroughly studying and identifying its impact. From what we surveyed we can have clear indicators that researchers and experts are looking at games as a tool to complement their work.

The field of serious games and Gamification has been gaining momentum with regards to tackling complex and challenging social problems. This has attracted both governments and non-governmental organizations to utilize it in their endeavors. This has been evident in many games and proof of concepts that exist already. 
One major research question remain vaguely answered: what impact does serious games and gaming concepts have on solving problems? It is not easy to answer this question without an extensive, carefully designed and longitudinal research studies. To ensure successful evaluation and realize positive impact of such games, it is advisable to ensure the following:

1. The need to clearly identifying and engaging main stakeholders in the early design phases of game development. NGO consultant and ICT for development experts has thoroughly analyzed and studied social problems and even developed tools and plans to inhibit their effects. They have valuable knowledge that can be used in game understanding and design.

2. Choosing development methodology with the aim to generate working prototype that is testable to collect valuable feedback that can be used in impact analysis. Agile software methodologies (e.g., Scrum [20]) have a well-established use in such applications. An early prototype will allow evaluation and impact analysis to start while the development is undergoing.

3. Adopting an evaluation methodology that is suitable for longitudinal analysis. Perhaps the Outcome Mapping methodology (OM) [21] is most suitable for this purpose. The methodology has been successfully used and adopted in ICT for development projects which are characterized by long period of implementation.

\section{CONCLUSION AND FUTURE WORK}

In this paper, we surveyed games that are categorized as those to tackle social problems and challenges. The survey, though it did not provide an inclusive list of all game that are considered as serious games, provided interesting examples of such. This we believe constitute a proof of the existence and the utilization of gaming concepts in addressing societal challenges. Two open research questions that remain to be investigated scientifically: (i) the impact of these games on inhibiting the effect of those challenges (ii) a detailed methodology to properly evaluate this. We provided analysis and recommendations to address these research questions. A natural follow up would be to extend the survey and propose a framework for the evaluation to produce quantitative scores.

\section{ACKNOWLEDGMENTS}

Our thanks to the experts who have contributed towards development of the template.

\section{REFERENCES}

[1] M. Papic and S. Noonan, "Social Media as a Tool for Protest," web article, Stratfor Global Intelligence. February 3 , 2011. [Retrieved 15/01/2014] from http://bit.ly/fE1Qnt.

[2] L. Cespedes and F. Martin, "Mobile Telephony in Rural Areas: The Latin American perspective," The i4d print magazine, VII No. 9 pp. 10-11, January-March 2011.

[3] E. Jaser and I. Ahmad, "ICT Intervention to Enhance Health Services to Mothers and Children in Remote Communities in Jordan," MobiCASE, volume 95:303-310

[4] E. Jaser and I. Ahmad, "Towards the Automatic Management of Vaccination Process in Jordan," Proceeding of the Sixth International Conference on Digital Society ICDS, pp. 50-54, Valencia, Spain 2012.

[5] E. Jaser, "Information and Mobile Technologies for Promoting Maternal-Child Health Care Status in Rural Areas of Jordan". iJIM 7(3) pp. 38-45 (2013)

[6] The Commission of the European Union. "ICT for Societal Challenges". 2013. ISBN: 978-92-79-29381-8. doi: $10.2759 / 4834$

[7] The Commission of the European Union. "The EU Framework Programme for Research and Innovation". [Retrieved November 24, 2013] from http://tinyurl.com/c93phjj.

[8] K. Oxland, "Gameplay and design". Addison Wesley; 1 edition. 20 May 2004. ISBN-13: 978-0321204677.

[9] Jivehealth, "Easy Eater game”. [Retrieved November 25, 2013] from http://jivehealth.com/.

[10] Wikipedia, "Dance Dance Revolution". [Retrieved November 25, 2013] from http://tinyurl.com/dlk5r /.

[11] T. Saunders, "Do active video games make kids more active?". Online blog, July 10, 2013. [Retrieved November 25, 2013] from http://tinyurl.com/khgx4up.

[12] H.G. Hoffman et al., "Water-friendly virtual reality pain control during wound care". J Clin Psychol, 60(2), pp. 189-95. 2004.

[13] L. Frum, "Video game aims to help young cancer patients". CNN. May 24, 2013. [Retrieved November 25, 2013] from http://tinyurl.com/pxybv5b.

[14] Wikipedia, "Theme Hospital Game”. Retrieved November 26, 2013 from http://en.wikipedia.org/wiki/Theme_Hospital.

[15] C. Heller, "Middle East peace a reality in new computer game". May 2, 2007. [Retrieved November 28, 2013] from http://tinyurl.com/q2f3c3n. 
[16] Wikipedia, "FoodForce". Retrieved November 26, 2013 from http://en.wikipedia.org/wiki/Food_Force

[17] R. Khaled and G. Yannakakis, "Village Voices: A Personalised and Adaptive Game for Conflict Resolution". Demo at the 8th International Conference on the Foundations of Digital Games (FDG) 2013.

[18] S. Deterding, D. Dixon, R. Khaled, and L. Nacke, "From game design elements to gamefulness: defining gamification". In Proceedings of the 15th International Academic MindTrek Conference: Envisioning Future Media Environments (MindTrek '11). ACM, New York, NY, USA, pp. 9-15. doi=10.1145/2181037.2181040.

[19] B. Stokes, "Video games have changed: Time to consider serious games". The Development Education Journal. 2005. [Retrieved August 20, 2007]. from www.dea.org.uk

[20] J. Schell, "The Art of Game Design: A book of lenses". CRC Press; 1st edition. August 4, 2008. ISBN-13: 9780123694966.

[21] C. Larman, "Agile and Iterative Development". Pearson Education. August 21, 2003. First Edition. ISBN-13: 9780131111554.

[22] S. Earl, F. Carden, and T. Smutylo, "Outcome Mapping: Building learning and reflection into development programs". International Development Research Center. 2001. ISBN: 0-88936-959-3.

[23] [23] D. Majumdar et al., "Creature-101: A Serious Game to Promote Energy Balance-Related Behaviors Among Middle School Adolescents". Games for Health Journal.October 2013, 2(5): pp. 280-290. 